\title{
openheart Activation of PPCI team in the octogenarian and nonagenarians population: real-world single- centre experience
}

\author{
Rajesh Kumar (i) , Cormac O'Connor, Jathinder Kumar, Brain Kerr (D) , \\ Ihtisham Malik, Ciarrai Homer, Syed Abbas, Samer Arnous, Ihsan Ullah, \\ Thomas John Kiernan
}

To cite: Kumar R, O'Connor C, Kumar J, et al. Activation of PPC team in the octogenarian and nonagenarians population: realworld single-centre experience. Open Heart 2021;8:e001709. doi:10.1136/ openhrt-2021-001709

Received 1 May 2021 Accepted 8 November 2021

Check for updates

(C) Author(s) (or their employer(s)) 2021. Re-use permitted under CC BY-NC. No commercial re-use. See rights and permissions. Published by BMJ.

Department of Cardiology, University Hospital Limerick Dooradoyle, Ireland

Correspondence to Dr Rajesh Kumar; rajesh2k7@ yahoo.com

\section{ABSTRACT}

Objective Advancement in healthcare provision has led to increasing octogenarian ST elevation myocardial infarction (STEMI) presentation to hospital for early revascularisation therapies. Limited literature to date exists to suggest octogenarian STEMI population; with majority of trials excluding these age group patients. Due to an ageing population, we expect increasing rates of STEMI in the octogenarian and nonagenarian population in the future. This study seeks to identify the outcomes of patients over the age of 80 presenting with STEMI and determine the factors associated with better or worse outcome.

Patients and methods This study is a single-centre retrospective observational study involving patients' age 80 or older presenting with STEMI between January 2014 and December 2019. Patient data were collected by chart review and analysis of the local STEMI database. Standard Bayesian statistics were employed for analysis.

Results 1301 patients presented with STEMI during this period. 159/1301 (12.2\%) were 80 years or older that fulfilled STEMI criteria, 35/159 (22.1\%) were medically managed. 107/124 (86.29\%) had angiographic evidence of acute total or partial thrombotic occlusion, and 97/107 were treated with primary percutaneous coronary intervention (PPCI). The activation ECG most commonly exhibited an anterior STEMI, while inferior STEMI ECGs had the strongest positive predictive value. $\mathrm{PPCl}$ group had a 30 -day mortality rate of $20 \%$ ( $p=0.07$ ) and 1 -year mortality was $22.4 \%$. Highest mortality was observed with cardiogenic shock, low ejection fraction, higher high sensitivity cardiac troponin $\mathrm{T}$ and creatinine at presentation. Conservatively managed patients had significant higher mortality rate ( $48 \%$ vs $22.4 \%$, $\mathrm{p}=0.005$ ) at 1 year.

Conclusion Patients over the age of 80 who present with STEMI and undergo PPCI have a significantly lower mortality rate at 1 year. These patients have a $77.6 \%$ survival at 1 year, with $92.4 \%$ likelihood of discharge to home (without need for long-term nursing home care). Cardiogenic shock in this group was associated with a 1 -year mortality of $87.5 \%$. Despite the advanced age, we suggest favourable outcomes described in the absence of patients presenting with cardiogenic shock.

\section{Key questions}

What is already known about this subject?

- Limited literature to date exists to suggest octogenarian ST elevation myocardial infarction (STEMI) population with outcomes; with majority of trials excluding these age group patients. Poor outcomes are associated with octogenarian and nonagenarian patients with STEMI compared to younger population.

What does this study add?

- This study is a real-world experience with modern analysis that enlightened clinicians across the globe of successful outcome of early coronary intervention in this age group, along with survival benefit and prognostic factors. To date, limited studies have such in-depth modern analysis of all the possible confounders in octogenarian population, as majority of trials exclude these age group patients that we included in this study. It also strengthens the point of survival benefit in early intervention cases.

How might this impact on clinical practice?

- With increasing global age, our study will give clear insight to cardiologist of early invasive strategies in elderly patients with STEMI, complications in this age group and confounding factors associated with worse outcome. Primary percutaneous coronary intervention in STEMI is a pivotal management step that should not be biased on age factor only. Advance frailty assessment scoring systems with clarified resuscitation orders and narrative should be made integral part for emergency octogenarian and nonagenarians care.

\section{INTRODUCTION}

Progress in the delivery of modern healthcare has led to an improved life expectancy worldwide, ${ }^{1}$ resulting in a larger population of elderly people living with chronic illness. Increasing age is a strong independent predictor of coronary artery disease (CAD), and when coupled with prolonged exposure to various risk factors for CAD (such 
as smoking, diabetes and hypercholesterolaemia), has contributed towards a substantial burden of CAD in the octogenarian and nonagenarian population. ${ }^{2}$

An increasing population of elderly patients with risk factors for CAD has resulted in an increase in the number of elderly patients presenting with ST elevation myocardial infarction (STEMI). ${ }^{3}$ The acute management of elderly patients with STEMI is fraught with difficulty due to a higher risk of mortality associated with STEMI in this age group alongside a higher risk of complications from any treatment undertaken. ${ }^{4}$ The increased incidence of STEMI in the very elderly is likely to continue to rise and delivery of care to this population will continue to prove challenging.

Accurate clinical histories, focused clinical assessment with prompt recognition of ECG patterns, are widely used ancillary tools for diagnosis of STEMI in all age groups. The diversity of chest pain symptoms and the communication challenges secondary to subsequent delirium or acute confusion in this population make the diagnosis of STEMI a diagnostic dilemma for clinicians. Additionally, there is higher prevalence of left ventricular hypertrophy and left bundle branch block patterns on ECGs in elderly patients compared with young. Frailty and age lead to decreased physiological reserve, with subsequent prolonged hospital stays and increased consumption of healthcare resources. ${ }^{5}$ Age itself is incorporated into scoring systems like Global Registry for Acute Coronary Event risk score and Thrombolysis In Myocardial Infarction score used for risk assessment in patients with coronary disease and is proportionally linked with worse outcomes. ${ }^{6}$ Thus, decisions on revascularisation and reperfusion therapies in octogenarians STEMIs are more challenging, with the incidence of octogenarians STEMIs likely to rise in coming years.

Primary percutaneous coronary intervention (PPCI) remains the optimal treatment approach towards STEMI ${ }^{7}$ and this should not be biased based on age, however, interventionalists will need to take into account patient suitability on a case-by case basis. ${ }^{8}$ More real-world data on the outcomes of STEMI in our ageing population are essential. In this study, we therefore aimed to provide a detailed modern analysis of real-world experience of octogenarians and nonagenarians patients with STEMI undergoing PPCI. We also sought to provide an insight into the importance and association of both mortality at 30 days and at 1 year with baseline demographics, clinical characteristics, laboratory parameters and procedural outcomes.

\section{METHODS}

A single-centre retrospective cohort analysis was conducted at the department of cardiology, University Hospital Limerick (UHL); a 24/7 PPCI centre in the midwest of Ireland. The study centre covers a large geographic area in Ireland that includes triage and transfer from other regional centres with various ethnicities and social backgrounds. Ethical approval was obtained from local ethical committee. Data were collected from electronic patient records and the local STEMI database at UHL. STEMI was defined as any patient with ECG changes based on WHO-ST elevation criteria, along with any symptom of cardiac ischemia (chest, shoulder, back, jaw or upper abdominal discomfort). All patients presenting with STEMI between January 2014 and December 2019 who were aged 80 years and above were included.

Baseline bloods at the time of admission and during hospitalisation were recorded for all patients including troponins and creatinine. Echocardiogram was performed for all patients and left ventricular ejection fraction (LVEF) was measured at the time of presentation or after the catheterisation procedure during index admission. The primary outcome of the study was all-cause mortality at 30 days and at 1 year. Patient demographics, procedural characteristics and biochemical results were also analysed. Statistical analysis was performed using IBM SPSS V.20 and a p value of $<0.05$ was considered significant. Mann-Whitney $\mathrm{U}, \chi^{2}$ and Fisher exact tests were used as appropriate.

\section{Patient and public involvement}

All octogenarian patients/guardians who presented to our centre were involved. Direct involvement of the all researcher group with the patient did not happen as it was a retrospective study. Proactive cardiologist's involved all the patients/guardian in the decision making, giving them education and empowerment of their symptoms, thus improving self awareness and as of the community of management of chronic cardiovascular illness. This study helped us encouraging adaptive, coherent response in the octogenarian patients with STEMI. The answer to the question 'Are we making the correct decision by subjecting elderly patients with comorbidities to interventional procedures?' leads us to make some necessary quality improvement reforms/changes to our health system to improve public and community health. We think that the results of our study will disseminate globally impacting the cure and outcome of elderly STEMI care.

\section{RESULTS}

A total of 159 patients were referred to cardiology services as emergency STEMI calls that met the electrocardiographic (WHO) criteria for STEMI and were age 80 or above. One hundred and twenty-four out of 159 $(77.9 \%)$ patients were deemed to be suitable candidates for transfer to the cardiac catheterisation laboratory, whereas 35 were managed conservatively due to unstable clinical status and/or burden of comorbidity (figure 1). The median age for all octogenarian and nonagenarian patients $(159 / 1301)$ was 85 years (range $80-97$ years).

All patients deemed suitable for transfer to the cardiac catheterisation laboratory $(n=124)$ were loaded with both aspirin $300 \mathrm{mg}$ and a P2Y12 antagonist such as clopidogrel 


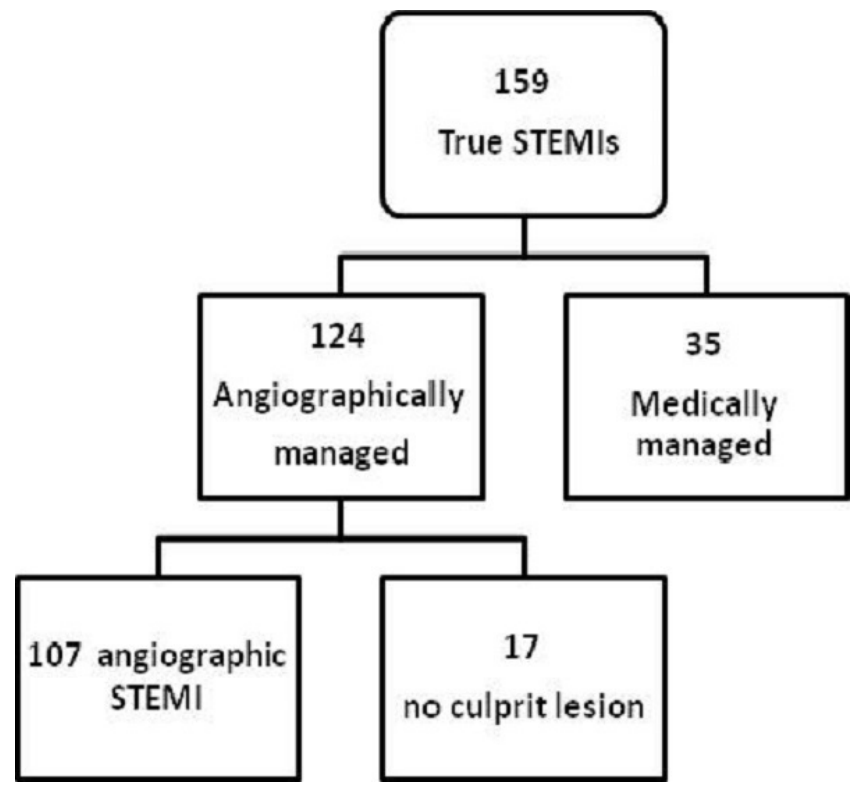

Figure 1 Flow chart showing the breakdown of octogenarian and nonagenarian patients into groups for analysis. STEMI, ST elevation myocardial infarction.

or ticagrelor. Radial access was the most common access site $(76.2 \%)$, followed by femoral access $(13.9 \%)$, and both radial and femoral access routes were required in $8.9 \%$ of cases (see table 1 ). There was no significant difference in 30-day mortality with regards to access site $(p=0.07)$. Of 124 patients who were brought to the cath lab, there was high proportion who had impaired LVEF (84.6\%); 51/124 (40.3\%) had an EF of 35\%-50\%, $43 / 124(34.6 \%)$ had an LVEF of $20 \%-35 \%$ and $11 / 124$ $(8.87 \%)$ had an LVEF of $<20 \%$. The activation ECG most commonly exhibited an anterior infarct (50\%), followed by inferior infarction $(38.7 \%)$ and lateral infarction $(3.8 \%)$. A bundle branch infarction was identified in $7 / 124(5.6 \%)$ of patients (see table 1$)$.

Of the 124 patient brought to the catheterisation laboratory, $107(62.2 \%)$ patients had angiographic evidence of acute total or partial thrombotic coronary occlusion.

The conservatively managed patients were older compared with those undergoing angiography (median (IQR), 85 (82.5-91) vs 83 (81-85), $\mathrm{p}=0.01$ ) (see table 2). Also, patients presenting from a nursing home were more likely to be treated medically and not undergo angiography (22.9\% vs $4.8 \%, \mathrm{p}=0.001$ ) (table 2 ). There were a number of other factors identified that were associated with the decision not to bring the patient to the catheterisation laboratory (see table 2). These included previous myocardial infarction (MI) (31.4\% vs $15.3 \%$, $\mathrm{p}=0.03$ ), previous percutaneous coronary intervention (PCI) $(22.9 \%$ vs $12.1 \%, \mathrm{p}=0.012)$, a previous cerebrovascular accident (CVA) $(14.3 \%$ vs $4 \%, \mathrm{p}=0.04)$ and the presence of peripheral vascular disease (PVD) $(14.3 \%$ vs $2.4 \%, \mathrm{p}=0.01$ ) along with their other comorbidities.

Overall mortality at 1 year was $26.4 \%(42 / 159)$, and patients in the PPCI group had numerically lower 30-day mortality compared with the conservative group $(20.6 \%$
Table 1 Detailed procedural characteristics of patients who received coronary angiography for a STEMI presentation

\begin{tabular}{|c|c|}
\hline Characteristics & $\mathrm{n}=124$ (\% population) \\
\hline \multicolumn{2}{|l|}{ Route } \\
\hline Radial & $95 / 124(76.2)$ \\
\hline Femoral & $18 / 124(13.9)$ \\
\hline Both routes & $11 / 124(8.9)$ \\
\hline \multicolumn{2}{|l|}{ Presenting blood pressure } \\
\hline $\mathrm{BP}>180 / 110$ & 10/124 (8.1) \\
\hline $\mathrm{BP}<90 / 60$ & $11 / 124(8.9)$ \\
\hline \multicolumn{2}{|l|}{ LVEF } \\
\hline$>55 \%$ & $03 / 124(3.2)$ \\
\hline $50 \%-55 \%$ & $16 / 124(12.1)$ \\
\hline $35 \%-50 \%$ & $51 / 124(40.3)$ \\
\hline $20 \%-35 \%$ & 43/124 (34.6) \\
\hline$<20 \%$ & $11 / 124(8.87)$ \\
\hline \multicolumn{2}{|l|}{ Presenting ECG } \\
\hline Inferior STEMI & $48 / 124(38.7)$ \\
\hline Anterior STEMI & $62 / 124(50)$ \\
\hline Posterior STEMI & 2/124 (1.6) \\
\hline Lateral STEMI & 04/124 (3.8) \\
\hline BBB STEMI & $07 / 124(5.6)$ \\
\hline No culprit vessel & $17 / 124(13.7)$ \\
\hline Emergency $\mathrm{CABG}$ & 03/124 (2.4) \\
\hline Culprit vessel & 107/124 (86.3) \\
\hline LMS & $04 / 107(3.7)$ \\
\hline LAD & 46/107 (42) \\
\hline LCX & $11 / 107$ (10.2) \\
\hline $\mathrm{RCA}$ & $36 / 107(33.6)$ \\
\hline Multi vessel & 10/107 (9.3) \\
\hline Use of stents during $\mathrm{PCl}$ & 97/107 (78.9) \\
\hline IABP & 09/107 (8.4) \\
\hline
\end{tabular}

Postprocedural TIMI flow

$\begin{array}{ll}\text { TIMI } 0 & 09 / 107(8.4) \\ \text { TIMI I } & 05 / 107(4.6) \\ \text { TIMI II } & 04 / 107(3.7) \\ \text { TIMI III } & 89 / 107(83.5)\end{array}$

BBB, bundle branch block; BP, blood pressure; CABG, coronary artery bypass grafting; IABP, intra-aortic balloon pump; LAD, left anterior descending; LCX, left circumflex; LMS, left main stem; LVEF, left ventricular ejection fraction; $\mathrm{PCl}$, percutaneous coronary intervention; RCA, right coronary artery; STEMI, ST elevation myocardial infarction; TIMI, Thrombolysis In Myocardial Infarction.

vs $37.1 \%$, respectively, $\mathrm{p}=0.07$ ) (see table 3 ). At 1 -year follow-up, there was a significantly higher mortality observed in the conservative group versus the PPCI group $(48.6 \%$ vs $22.4 \%$, respectively, $\mathrm{p}=0.005)$ (table 3 ) (figure 2). Average length of stay for patients brought to catheterisation laboratory was $5.53 \pm 8.2$ days. 


\begin{tabular}{lccc}
\hline \multicolumn{1}{l}{ Table 2} & Factors influencing the decision to bring the patient for primary coronary angiography & \\
\hline Characteristic & Cathlab (n=124) & Conservative/medical management only (n=35) & P value \\
\hline Age, years, median (IQR) & $83(81-86)$ & $85(82.5-91)$ & 0.016 \\
\hline Male gender, \% (n) & $52.4(65 / 124)$ & $45.7(16 / 35)$ & 0.44 \\
\hline Admitted from nursing home, \% (n) & $4.8(6 / 124)$ & $22.9(8 / 35)$ & 0.001 \\
\hline Hypertension, \% (n) & $57.3(71 / 124)$ & $71.4(25 / 35)$ & 0.17 \\
\hline Diabetes, \% (n) & $8.9(11 / 124)$ & $11.4(4 / 35)$ & 0.57 \\
\hline Previous MI, \% (n) & $15.3(19 / 124)$ & $31.4(11 / 35)$ & 0.019 \\
\hline Hypercholesterolaemia, \% (n) & $50(62 / 124)$ & $60(21 / 35)$ & 0.62 \\
\hline Never smoked, \% (n) & $47.6(59 / 124)$ & $68.6(24 / 35)$ & 0.003 \\
\hline Previous CABG, \% (n) & $5.6(7 / 124)$ & $5.7(2 / 35)$ & 0.7 \\
\hline Previous PCl, \% (n) & $12.1(15 / 124)$ & $22.9(8 / 35)$ & 0.012 \\
\hline Previous CVA, \% (n) & $4(5 / 124)$ & $14.3(5 / 35)$ & 0.04 \\
\hline Previous PVD, \% (n) & $2.4(3 / 124)$ & $14.3(5 / 35)$ & 0.005 \\
\hline Cardiogenic shock, \% (n) & $13.7(17 / 124)$ & $20(7 / 35)$ & 0.25 \\
\hline Tachycardia on admission, \% (n) & $14.5(18 / 124)$ & $21.5(11 / 48)$ & 0.007 \\
\hline Bradycardia on admission, \% (n) & $13.9(17 / 124)$ & $14.5(07 / 48)$ & 0.019 \\
\hline Median hs-cTnT (IQR) & $3232(1319-7721)$ & $1305(1145-7385)$ & $<0.001$ \\
\hline Median creatinine (IQR) & $86.5(59.8-113)$ & $98(78-120)$ & 0.245 \\
\hline
\end{tabular}

CABG, coronary artery bypass grafting; CVA, cerebrovascular accident; hs-cTnT, high sensitivity cardiac troponin T; MI, myocardial infarction; $\mathrm{PCl}$, percutaneous coronary intervention; PVD, peripheral vascular disease.

In the conservative managed group, both 30-day and 1-year mortality were high among patients who had history of hypertension (28\% vs $44 \%$ ), diabetes mellitus ( $50 \%$ vs $75 \%)$, previous PCI $(75 \%$ vs $75 \%)$ and coronary artery bypass grafting (CABG) (50\% vs 100\%) (see table 4).
Of the patients brought to the cardiac catheterisation laboratory $(\mathrm{n}=124), 16$ patients $(12.9 \%)$ exhibited cardiogenic shock, with 9 of these $(56.25 \%)$ requiring intraaortic balloon pump insertion; $2.4 \%(3 / 124)$ required emergency CABG, $1.6 \%$ (2/124) patient had confirmed ischaemic CVA on index admission, 2.4\% (3/124) had

Table 3 Comparison of patients presenting with STEMI (conservative vs revascularised)

\begin{tabular}{lccc}
\hline Characteristic & PPCI (n=107) & Conservative (n=35) & P value \\
\hline Age, years, median (IQR) & $83(81-85)$ & $85(82.5-91)$ & 0.01 \\
\hline Male gender, \% (n) & $53.3(57 / 107)$ & $45.7(16 / 35)$ & 0.44 \\
\hline Admitted from nursing home, \% (n) & $2.8(3 / 107)$ & $22.9(8 / 35)$ & 0.001 \\
\hline Hypertension, \% (n) & $59.8(64 / 107)$ & $71.4(25 / 35)$ & 0.22 \\
\hline Diabetes mellitus, \% (n) & $10.3(11 / 107)$ & $11.4(4 / 35)$ & 0.99 \\
\hline Hypercholesterolaemia, \% (n) & $51.4(55 / 107)$ & $60(21 / 35)$ & 0.38 \\
\hline Never smoked, \% (n) & $43(46 / 107)$ & $68.6(24 / 35)$ & 0.01 \\
\hline Previous CABG, \% (n) & $6.5(7 / 107)$ & $5.7(2 / 35)$ & 0.99 \\
\hline Previous PCI, \% (n) & $12.1(13 / 107)$ & $22.9(8 / 35)$ & 0.12 \\
\hline Previous CVA, \% (n) & $4.7(5 / 107)$ & $14.3(5 / 35)$ & 0.07 \\
\hline Previous PVD, \% (n) & $2.8(3 / 107)$ & $14.3(5 / 35)$ & 0.02 \\
\hline Previous MI, \% (n) & $15(16 / 107)$ & $31.4(11 / 35)$ & 0.05 \\
\hline Cardiogenic shock on admission, \% (n) & $20(7 / 35)$ & 0.6 \\
\hline 30-day mortality, \% (n) & $15(16 / 107)$ & $37.1(13 / 35)$ & 0.07 \\
\hline One-year mortality, \% (n) & $20.6(22 / 107)$ & $48.6(17 / 35)$ & 0.005 \\
\hline
\end{tabular}

CABG, coronary artery bypass grafting; $\mathrm{CVA}$, cerebrovascular accident; $\mathrm{MI}$, myocardial infarction; $\mathrm{PCl}$, percutaneous coronary intervention; PPCl, primary percutaneous coronary intervention; PVD, peripheral vascular disease; STEMI, ST elevation myocardial infarction. 


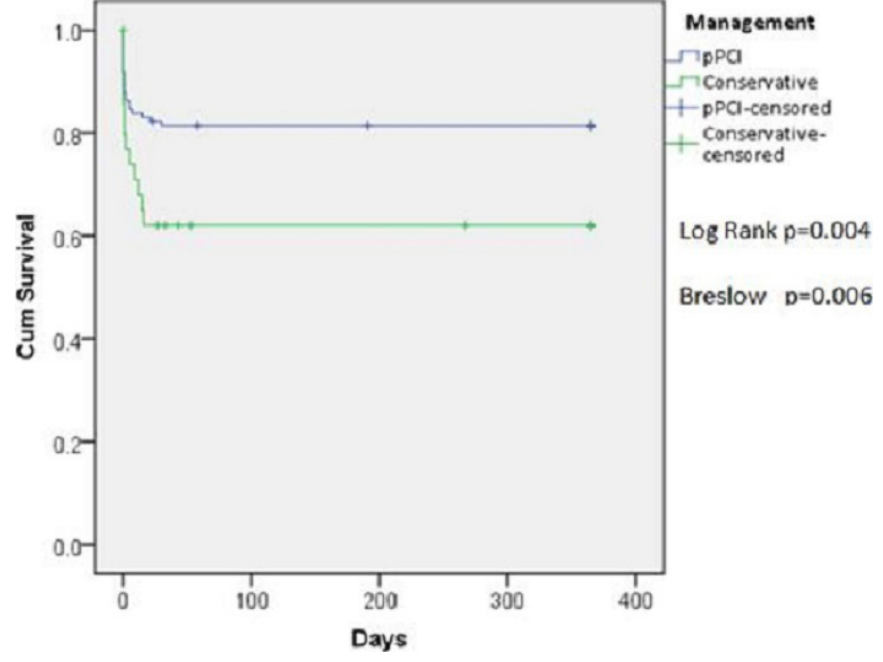

Figure 2 Kaplan-Meier curve showing survival for the $\mathrm{PPCl}$ and conservative management groups. $\mathrm{PPCl}$, primary percutaneous coronary intervention.

intracranial bleed during hospitalisation (one patient out of which was on anticoagulation), while $1.6 \%$ (2/124) patients had significant bleeding (haemoglobin drop $\geq 3 \mathrm{~g}$ ) requiring blood transfusion during inpatient stay.

The presence of cardiogenic shock was associated with $87.5 \%$ mortality in those who were brought to the catheterisation laboratory. In those who were brought for intervention, patients presenting in cardiogenic shock were associated with the strongest risk of mortality at 1 year $(\mathrm{OR}=63.1 \quad(95 \%$ CI 16.1 to 336.6, $\mathrm{p}<0.001))$ and possess higher peak high sensitivity cardiac troponin $\mathrm{T}$ (2103 vs $6717, \mathrm{p}=0.010)$ and creatinine levels (92.0 vs 120 , $\mathrm{p}=0.001$ ), while a baseline $\mathrm{LVEF} \geq 40 \%$ was associated with a reduced likelihood of mortality at 1 year $(\mathrm{OR}=0.33$ (95\% CI 0.13 to $0.82, p=0.05)$ ). Cardiogenic shock at presentation was a strong discriminator for predicting
Table 5 ORs of variables associated with mortality at 1 year

\begin{tabular}{lclc}
\hline Variable & OR & $\mathbf{9 5 \%}$ Cl & P value \\
\hline LVEF $\geq 40 \%$ & 0.33 & 0.13 to 0.82 & 0.05 \\
Systolic blood pressure & 0.99 & 0.97 to 1 & 0.1 \\
Cardiogenic shock & 63.1 & 16.1 to 336.6 & $<0.001$ \\
Baseline creatinine & 1.02 & 1.01 to 1.03 & 0.001 \\
Log troponin & 1.7 & 1 to 3.7 & 0.1 \\
\hline
\end{tabular}

LVEF, left ventricular ejection fraction.

mortality at 1 year (area under the curve $=0.84,95 \% \mathrm{CI}$ 0.75 to 0.94 ) and outperformed all other predictors. The independent variables with a significant association with mortality at 1 year are outlined in table 5 .

At discharge, a relatively small proportion of patients $6 / 105(5.7 \%)$ admitted from home required discharge to a long-term nursing home placement. Patients transferred to the catheterisation laboratory in comparison to medically managed showed a long survival at 1 year time (figure 2).

\section{DISCUSSION}

One hundred and fifty-nine patients over the age of 80 were referred as a 'code STEMI', representing 12.2\% $(159 / 1268)$ of all STEMIs during the 5-year study period. This proportion of octogenarians is similar to other published data elsewhere ${ }^{8-11}$ and is reflective of the increasing trend of an ageing global population. This study included a large cohort of patients with STEMI that were brought either directly to a PCI centre or alternatively transferred after assessment in a regional hospital without facilities for PPCI. The decision to bring an

\begin{tabular}{lccc}
\hline \multicolumn{4}{l}{ Table 4 Characteristics with subgroup 30-day and 1-year mortality for the conservative management group } \\
\hline Characteristic & $\mathbf{n}=\mathbf{3 5}$ & \multicolumn{3}{l}{ 30-day mortality } & 1-year mortality \\
\hline Age, years, median (IQR) & $85(82.5-91)$ & & \\
\hline Male gender, \% (n) & $45.7(16 / 35)$ & $37.5(6 / 16)$ & $43.8(7 / 16)$ \\
\hline Admitted from nursing home, \% (n) & $22.9(8 / 35)$ & $25(2 / 8)$ & $37.5(3 / 8)$ \\
\hline Hypertension, \% (n) & $71.4(25 / 35)$ & $28(7 / 25)$ & $44(11 / 25)$ \\
\hline Diabetes, \% (n) & $11.4(4 / 35)$ & $50(2 / 4)$ & $75(3 / 4)$ \\
\hline Previous MI, \% (n) & $31.4(11 / 35)$ & $36.4(4 / 11)$ & $45.5(5 / 11)$ \\
\hline Hypercholesterolaemia, \% (n) & $60(21 / 35)$ & $28.6(6 / 21)$ & $42.9(9 / 21)$ \\
\hline Never smoked, \% (n) & $68.6(24 / 35)$ & $33.3(8 / 24)$ & $45.8(11 / 24)$ \\
\hline Previous CABG, \% (n) & $5.7(2 / 35)$ & $50(1 / 2)$ & $100(2 / 2)$ \\
\hline Previous PCl, \% (n) & $22.9(8 / 35)$ & $75(6 / 8)$ & $75(6 / 8)$ \\
\hline Previous CVA, \% (n) & $14.3(5 / 35)$ & $11.4(4 / 35)$ & $14.3(5 / 35)$ \\
\hline Previous PVD, \% (n) & $14.3(5 / 35)$ & $40(2 / 5)$ & $40(2 / 5)$ \\
\hline Cardiogenic shock an admission, \% (n) & $20(7 / 35)$ & $14.3(1 / 7)$ & $28.6(2 / 7)$ \\
\hline
\end{tabular}

CABG, coronary artery bypass grafting; CVA, cerebrovascular accident; $\mathrm{MI}$, myocardial infarction; $\mathrm{PCl}$, percutaneous coronary intervention; PVD, peripheral vascular disease. 
elderly patient to the catheterisation laboratory can be a difficult one.

Those who were deemed not appropriate for catheterisation laboratory transfer were more likely to exhibit a higher rate of comorbidities (such as previous MI, dementia, PVD, CVA) and surrogates thereof (such as transfer from nursing home). Patients that were deemed appropriate for angiography and who had a lesion requiring revascularisation had lower mortality at 1 year than those treated conservatively.

The benefits of reperfusion therapy to restore coronary flow have been investigated previously, and it has been reported that there is no difference in relative risk reduction of PPCI in elderly compared with non-elderly patients. ${ }^{12}$ Regarding overall benefit, the increased risk of angiographic complications in the very elderly is offset by the fact that elderly patients have higher rates of morbidity and mortality when presenting with STEMI. Successful restoration of coronary flow is associated with increased survival ${ }^{13}$ and this was shown at 1 year in this cohort. Across all-comers with STEMI over the age of 80 , the rate of mortality was $26.41 \%$. Mortality was $20.6 \%$ among patients with angiographic evidence of a coronary occlusion.

The majority of patients who were transferred for cardiac catheterisation and who died within 30 days presented with cardiogenic shock (14/22, 63.63\%). Coincidently, those who were brought to the cardiac catheterisation laboratory and had cardiogenic shock exhibited an extremely high mortality at 30 days $(87.5 \%)$. Of those who were brought to the catheterisation laboratory, the presence of cardiogenic shock was associated with a significantly higher rate of death at 30 days (HR $9.95(95 \%$ CI 5.0061 to $19.7888, \mathrm{p}=<0.00001)$ ). Excluding those with cardiogenic shock, the observed 30-day mortality was $8.7 \%$ (8/91). This data highlights the high mortality associated with cardiogenic shock in patients over the age of 80 years. Overall levels of mortality exhibited in this cohort were similar to other previously reported cohorts, ${ }^{14-16}$ and the 30-day and 1-year mortality in our study are very similar to any other study reports in octogenarian and nonagenarian populations. ${ }^{8-11}$

Few studies have reported the impact of procedural characteristics on the outcome in patients over 80 years. ${ }^{17} 18$ In this cohort, successful radial access was attained in $76.2 \%$ of cases. The prevalence of cardiogenic shock was $14.9 \%$ in those brought to the catheterisation laboratory and was associated with a very high rate of mortality $(87.5 \%)$.

This study was a retrospective cohort analysis, and as such is at inherent risk of recall bias, reporting bias and incomplete/inaccurate patient-level metrics. The data collected in this study, however, were from a highly functioning prospective local STEMI database, thus improving the integrity of the data and allowing for accurate outcome tracking.

Our study enrolled all-comers over the age of 80 presenting with STEMI, including those with cardiogenic shock. We did not have any frailty assessment scoring system for acute elderly patients with STEMI but the interventionalists in the study centre are proactive in revascularising patients over the age of 80 who exhibit good baseline and no contraindication to either angiography or PCI. These features of the programme served to highlight patients in whom bad outcomes are likely in an interventional strategy (ie, those presenting with cardiogenic shock).

We consider this study to be quite representative of modern practice and provides an insight into the difficulties faced when dealing with an ageing population. Advance frailty assessment scoring systems with clarified resuscitation orders and care narrative should be made integral part for emergency octogenarian and nonagenarians STEMI care. This data shows that patients over the age of 80 who are selected to go to the catheterisation laboratory with STEMI exhibit good outcomes. In patients who have cardiogenic shock on presentation, however, have a high rate of mortality at 30 days.

\section{CONCLUSION}

This study demonstrates that there is a high mortality rate with STEMI in those aged 80 years or above $(\sim 1$ out 4 at 1 year), however, patients who are treated with PPCI have a significantly lower mortality rate at 1 year. The incidence of STEMI in patients over the age of 80 is likely to continue to rise and this may prove challenging. PPCI remains the optimal treatment approach towards STEMI and this should not be biased based on age, however, interventionalists will need to take into account patient suitability on a case-by case basis.

Octogenarians who undergo angiography and PPCI as required have $77.6 \%$ survival at 1 year and a $92.4 \%$ likelihood of discharge to home; without need for long-term nursing home care. Despite the advanced age-profile of this cohort, we suggest favourable outcomes in the absence of cardiogenic shock and left ventricular pump failure.

Contributors RK collected data, electronic records and historical records with chart review of the patients. Designing, ethical approval and consent of the study. Collection, anonymise and securing data. Responsible for writing primary manuscript, references, literature review and correspondence with all the authors. CO'C wrote and edited manuscript with subsection comments and relevant references. Performing statistical work and was also involved in designing the study. JK collected the data, design and editing. BK edited the manuscript with area of focus of statistical analysis. IM performed data collection and electronic chart reviews. $\mathrm{CH}$ performed majority data collection, compilation, security and electronic chart reviews. SAb edited the manuscript with special consideration to the area of focus of geriatric interventions. SAr edited the manuscript with special consideration to the area of focus of interventional procedures. IU edited the manuscript with special consideration to the area of focus of interventional procedures. TJK edited the manuscript, principle idea sharing with expert reviews and suggestions. RK is responsible for the overall content as the guarantor.

Funding The authors have not declared a specific grant for this research from any funding agency in the public, commercial or not-for-profit sectors.

Competing interests None declared.

Patient consent for publication Not applicable.

Ethics approval Local ethics committee, University of Limerick Hospital Group, Ireland.

Provenance and peer review Not commissioned; externally peer reviewed. 
Data availability statement All data relevant to the study are included in the article or uploaded as supplementary information. It is a retrospective analysis of patients with STEMI in University Hospital Limerick, Ireland.

Open access This is an open access article distributed in accordance with the Creative Commons Attribution Non Commercial (CC BY-NC 4.0) license, which permits others to distribute, remix, adapt, build upon this work non-commercially, and license their derivative works on different terms, provided the original work is properly cited, appropriate credit is given, any changes made indicated, and the use is non-commercial. See: http://creativecommons.org/licenses/by-nc/4.0/.

ORCID iDs

Rajesh Kumar http://orcid.org/0000-0002-8002-1551

Brain Kerr http://orcid.org/0000-0002-4071-8960

\section{REFERENCES}

1 World Health Organisation. Methods and data sources for life tables 1990-2015 (global health estimates technical paper WHO/HIS/IER/ GHE/2016.2. WHO, 2018

2 Carro A, Kaski JC. Myocardial infarction in the elderly. Aging Dis 2011;2:116-37.

3 Alexander KP, Newby LK, Cannon CP, et al. Acute coronary care in the elderly, part I: Non-ST-segment-elevation acute coronary syndromes: a scientific statement for healthcare professionals from the American heart association Council on clinical cardiology: in collaboration with the Society of geriatric cardiology. Circulation 2007;115:2549-69.

4 Gharacholou SM, Alexander KP, Chen AY, et al. Implications and reasons for the lack of use of reperfusion therapy in patients with STsegment elevation myocardial infarction: findings from the crusade initiative. Am Heart J 2010;159:757-63.

5 Fried LP, Tangen CM, Walston J, et al. Frailty in older adults: evidence for a phenotype. J Gerontol A Biol Sci Med Sci 2001;56:M146-57.

6 Bueno H, Fernández-Avilés F. Use of risk scores in acute coronary syndromes. Heart 2012;98:162-8.

7 Andersen HR, Nielsen TT, Rasmussen K, et al. A comparison of coronary angioplasty with fibrinolytic therapy in acute myocardial infarction. N Engl J Med 2003;349:733-42.
8 Bromage DI, Jones DA, Rathod KS, et al. Outcome of 1051 octogenarian patients with ST-segment elevation myocardial infarction treated with primary percutaneous coronary intervention: observational cohort from the London heart attack group. J Am Heart Assoc 2016;5:e003027.

9 Caretta G, Passamonti E, Pedroni PN, et al. Outcomes and predictors of mortality among octogenarians and older with ST-segment elevation myocardial infarction treated with primary coronary angioplasty. Clin Cardiol 2014;37:n/a-9.

10 Antonsen L, Jensen LO, Terkelsen CJ, et al. Outcomes after primary percutaneous coronary intervention in octogenarians and nonagenarians with ST-segment elevation myocardial infarction: from the Western Denmark heart registry. Catheter Cardiovasc Interv 2013;81:912-9.

11 Sim WL, Mutha V, UI-Haq MA, et al. Clinical characteristics and outcomes of octogenarians presenting with ST elevation myocardial infarction in the Australian population. World J Cardiol 2017:9:437-41.

12 Newell MC, Henry JT, Henry TD, et al. Impact of age on treatment and outcomes in ST-elevation myocardial infarction. Am Heart J 2011;161:664-72.

13 Sorajja P, Gersh BJ, Costantini C, et al. Combined prognostic utility of ST-segment recovery and myocardial blush after primary percutaneous coronary intervention in acute myocardial infarction. Eur Heart J 2005;26:667-74.

14 Goldberg RJ, Gore JM, Alpert JS, et al. Cardiogenic shock after acute myocardial infarction. incidence and mortality from a community-wide perspective, 1975 to 1988. N Engl J Med 1991;325:1117-22.

15 Koeth O, Zahn R, Heer T, et al. Gender differences in patients with acute ST-elevation myocardial infarction complicated by cardiogenic shock. Clin Res Cardiol 2009;98:781-6.

16 Shaefi S, O'Gara B, Kociol RD, et al. Effect of cardiogenic shock hospital volume on mortality in patients with cardiogenic shock. $J$ Am Heart Assoc 2015;4:e001462.

17 de Boer M-J, Ottervanger JP, Suryapranata $\mathrm{H}$, et al. Old age and outcome after primary angioplasty for acute myocardial infarction. $J$ Am Geriatr Soc 2010;58:867-72.

18 Brodie BR, Stone GW, Cox DA, et al. Impact of treatment delays on outcomes of primary percutaneous coronary intervention for acute myocardial infarction: analysis from the CADILLAC trial. Am Heart $J$ 2006;151:1231-8. 